\title{
Diagnostic Criteria for the Asthma-COPD Overlap (ACO) Still Room for Improvement
}

\author{
Alexa Nuñez and Marc Miravitlles* \\ Department of Pneumology, University Hospital Vall d' Hebron, Spain
}

Submission: March 10, 2017; Published: May 31, 2017

*Corresponding author: Marc Miravitlles, Department of Pneumology, University Hospital Vall d’ Hebron, Spain, Email: mmiravitlles@vhebron.net

\section{Introduction}

Chronic obstructive pulmonary disease (COPD) is a heterogeneous disease in which the clinical presentation and prognosis vary according to the phenotype [1]. In the last years, one of the phenotypes of COPD, that is recognized as the AsthmaCOPD Overlap (ACO) has received increasing attention.

In contrast with the remaining COPD phenotypes, patients with ACO present an elevated reversibility of airflow obstruction as well as a greater degree of eosinophilic bronchial inflammation, thereby demonstrating greater response to inhaled corticosteroid (ICS) treatment [2-4]. These characteristics are suggestive of asthma and can be explained by a history of asthma during youth being an independent risk factor for the development of COPD in smokers [5] (Figure 1).

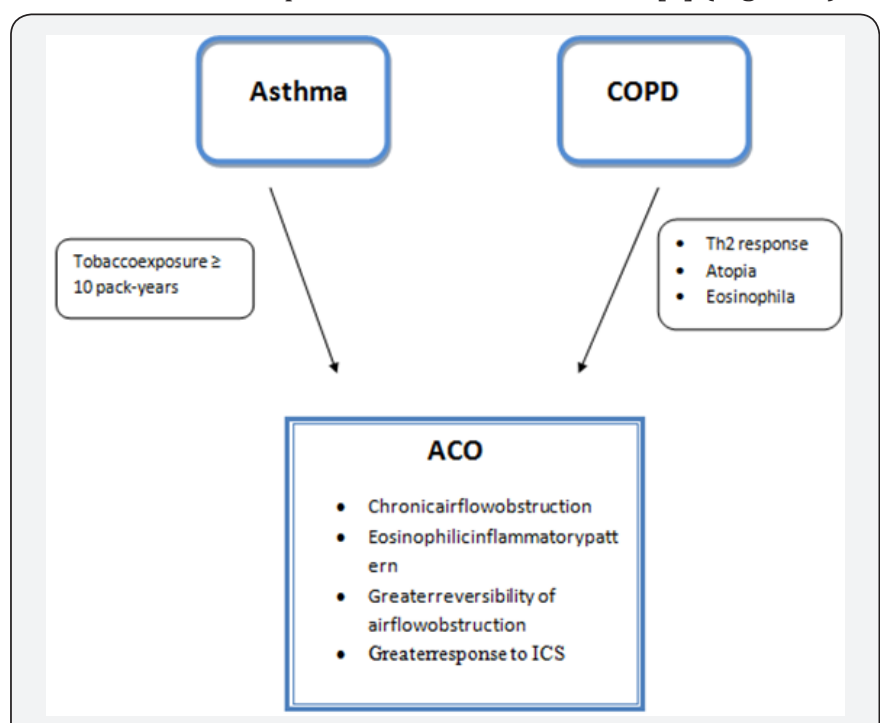

Figure 1: Etiopathogenesis of ACO.

From a clinical point of view, patients with ACO present more symptoms, have a worse quality of life and a higher risk of exacerbations than the remaining patients with COPD, but they have a better survival. In the CHAIN study including
125 COPD patients labeled as having ACO and who fulfilled specific characteristics associated with asthma according to some diagnostic criteria [major criteria: bronchodilator test (BDR) $>400 \mathrm{ml}$ and $15 \%$ or a history of asthma; minor criteria: eosinophilia $>5 \%$, IgE $>100 \mathrm{IU} / \mathrm{ml}$ or two BDR $>200 \mathrm{ml}$ and $12 \%]$ were found to have a greater one year survival compared to the remaining patients with COPD without ACO [6].

Likewise, the cohort study by Hokkaido followed 268 patients labeled as having ACO who did not have a previous diagnosis of asthma but fulfilled the characteristics of asthma (reversibility of airflow obstruction $\geq 12 \%$ and $200 \mathrm{ml}$, eosinophilia $\geq 300$ eosinophils/ $\mu \mathrm{l}$ and/or atopy (specific IgE positive for at least one inhaled antigen), and it was observed that despite these patients presenting a worse score in the St. George quality of life questionnaire, they had a lower mortality at 10 years compared to non ACOS patients probably because of greater response to anti inflammatory treatment with ICS [7].

Globally, the prevalence of ACOS reported varies greatly due to the different diagnostic criteria used. Different epidemiological studies in which ACOS is defined as patients with COPD diagnosed with asthma before the age of 40 described prevalences of $13 \%$ and $17 \%[6,8]$. Using the same definition, a multicenter, cross-sectional, observational study carried out in Spain including 3125 patients with COPD in primary care and specialized centers reported a prevalence of ACO of 15.9\% [9]. The prevalence of ACO was determined to be between 1.6 and $4.5 \%$ in the general adult population and between $15 \%$ and 25 $\%$ in the adult population with COPD.

In the last years attempts have been made to define the diagnostic criteria of this phenotype, but no definitive consensus has been achieved. In Spain, a diagnostic consensus by the Spanish COPD Guidelines (GesEPOC) was initially proposed, including very restrictive criteria in which 2 major criteria or 1 major and 2 minor criteria had be fulfilled for a patient to be defined as having ACO. The major criteria included a very positive 
$\mathrm{BDR} \geq 400 \mathrm{ml}$ and $15 \%$ compared to baseline, eosinophilia in sputum and a personal history of asthma (prior to 40 years of age), and the minor criteria were an elevated total IgE, a history of atopy and a positive BDR $\geq 200 \mathrm{ml}$ and $12 \%$ on at least two occasions [10]. Thereafter, an agreement between the Global Initiative for Asthma (GINA) and the Global initiative for Chronic Obstructive Lung Disease (GOLD) defined the ACO phenotype as persistent airflow limitation with characteristics of both asthma and COPD but did not clearly specify how many criteria should be met to establish a diagnosis of ACO [11].

Later in 2016, a consensus was made among specialists in North America, Europe and Asia, proposing 3 major criteria (persistent airflow limitation $<0.70$ in patients over 40 years of age, exposure to smoking of at least 10 packs-year or the equivalent in biomass smoke exposure, a documented history of asthma before age 40 or BDR $>400 \mathrm{ml}$ in FEV1) and 3 minor criteria (documented history of atopy or allergic rhinitis, $\mathrm{BDR} \geq 200 \mathrm{ml}$ and $12 \%$ on at least 2 occasions, peripheral eosinopilia $\geq 300$ eosinophils $/ \mu \mathrm{L}$ ). For a diagnosis of ACO, 3 major criteria and at least one of the minor criteria proposed had to be met [12].

More recently, the new consensus between GesEPOC and the Spanish Guidelines for the Management of Asthma (GEMA) defined overlapping of asthma and COPD (ACO) as the presence of chronic persistent airflow limitation, in a smoker or former smoker [tobacco exposure $\geq 10$ pack-years] with a concomitant diagnosis of asthma or with characteristics of asthma such as very positive $B D R(\geq 15 \%$ and $\geq 400 \mathrm{ml}$ ) and/or blood eosinophilia ( $\geq 300$ eosinpophils $/ \mu \mathrm{L}$ ). Thus, the ACO phenotype includes not only smoker asthma patients who develop persistent airflow obstruction but also COPD with characteristics of asthma. To fulfill this definition, airflow limitation must be persistent over time, current or past smoking should be the main risk factor, and the patient must present clinical, biological or functional characteristics of asthma [13].

The diagnosis is sequential; the presence of chronic airflow obstruction must first be confirmed with a post bronchodilator FEV1/FVC ratio $<0.70$ in patients over 35 years of age who are active or former smokers of at least 10 pack-years. In cases of doubtful diagnosis, the patients should undergo spirometry evaluation after at least 6 months of treatment with an ICS and a long-acting $\beta 2$ agonist (LABA). In case of reversibility of airflow obstruction the diagnosis is asthma. After confirming the persistence of chronic airflow obstruction, the current diagnosis of asthma should be confirmed by a family or personal history or asthma and/or atopy with respiratory symptoms (wheezing, cough, chest oppression) or upper airway inflammation or daily variability of $\mathrm{PEF} \geq 20 \%$ or exhaled nitric oxide fraction (FENO $\geq 50 \mathrm{ppb}$ ). If the diagnosis of asthma cannot be established, the diagnosis of ACO is confirmed if a patient with COPD presents features of asthma: a very positive $\operatorname{PBD}(\geq 15 \%$ and $\geq 400 \mathrm{ml})$ and/or the presence of eosinophilia in blood ( $\geq 300$ eosinophils/ $\mu \mathrm{L})[13]$.

Eosinophilia has shown to be a good biomarker to identify COPD patients showing better response to ICS treatment who fulfill the ACO criteria. However, the cut-off value is controversial. In one study comparing stable COPD patients without ACO with another stable COPD group with ACO, the patients with ACO presented blood eosinophil concentrations double those observed in the COPD group without ACO [14]. Studies comparing eosinophilc inflammation in blood and sputum have suggested that a cut-off value of $\geq 300$ eosinophils/ $\mu$ Lin blood is a good predictor of eosinophilia in sputum [15]. Different consensuses recommend this cut-off of $\geq 300$ eosinophils $/ \mu \mathrm{L}$ in peripheral blood $[12,13]$.

With regard to the treatment of patients fulfilling ACO criteria, the objectives are to prevent exacerbations as well as maintain acceptable control of the symptoms and reduce the grade of bronchial obstruction. The importance of diagnosing ACO is to identify patients with COPD who require treatment with ICS plus LABA from early phases of the disease.

Thus, the new GesEPOC-GEMA consensus establishes a combination of LABA/ICS as the initial treatment. However, a combination of choice cannot be recommended since no study has compared different combinations [13]. Therefore, the elevated doses of ICS currently recommended for the treatment of COPD are associated with a greater incidence of adverse effects, and a dose-response relationship with clinical efficacy has not been demonstrated. Thus, intermediate doses of ICS are recommended for the maintenance of these patients [16].

In more severe cases a long-acting anti cholinergic (LAMA) may be added, constituting triple therapy (LABA/ICS/LAMA). Although in the future some of these patients, particularly the most severe not controlled with triple therapy, may be candidates to treatment with new biological drugs, there are no specific clinical trials on patients with ACO with this particular phenotype.

Likewise, smoking cessation should be insisted upon as should respiratory rehabilitation and the use of nasal anti inflammatories and oxygen therapy in indicated cases [13].

\section{References}

1. Decramer M, Janssens W, Miravitlles M (2012) Chronic obstructive pulmonary disease. Lancet 379 (9823): 1341-1351.

2. Disantostefano RL, Li H, Rubin DB, Stempel DA (2013) Which patients with chronic obstructive pulmonary disease benefit from the addition of an inhaled corticosteroid to their bronchodilator? A clusteranalysis. BMJ Open 3(4): e001838.

3. Kitaguchi Y, Komatsu Y, Fujimoto K, Hanaoka M, Kubo K (2012) Sputum eosinophilia can predict responsiveness to inhaled corticosteroid treatment in patients with overlap syndrome of COPD and asthma. Int J ChronObstruct Pulmon Dis 7: 283-289. 
4. Louie S, Zeki AA, Schivo M, Chan AL, Yoneda KY, et al. (2013) The asthma-chronic obstructive pulmonary disease overlap syndrome: pharmacotherapeutic considerations. Expert Rev Clin Pharmacol 6(2): 197-219.

5. Barrecheguren M, Esquinas C, Miravitlles M (2015) The asthmachronic obstructive pulmonary disease overlap syndrome (ACOS): opportunities and challenges. Curr Opin Pulm Med 21(1): 74-79.

6. Cosio BG, Soriano JB, López-Campos JL, Calle-Rubio M, Soler-Cataluna JJ, et al. (2016) Defining the Asthma-COPD Overlap Syndrome in a COPD Cohort. Chest 149: 45-52.

7. Suzuki M, Makita H, Konno S, Shimizu K, Kimura H, et al. (2016) Asthma-like Features and Clinical Course of Chronic Obstructive Pulmonary Disease. An Analysis from the Hokkaido COPD Cohort Study. Am J Respir Crit Care Med 194(11): 1358-1365.

8. Hardin M, Silverman EK, Barr RG, Hansel NN, Schroeder JD, et al. (2011) The clinical features of the overlap between COPD and asthma. Respir Res 12:127.

9. Barrecheguren M, Román-Rodríguez M, Miravitlles M (2015) Is a previous diagnosis of asthma a reliable criterion for asthma-COPD overlap syndrome in a patient with COPD? Int J Chron Obstruct Pulmon Dis 10: 1745-1752.

10. Juan José S, Borja C, José LI, Luis LC, José M, et al. (2012) Documento de consenso sobre el fenotipo mixto EPOC-asma. Arch Bronconeumol 48(9): 331-337.
11. GINA and Global Initiative for Chronic Obstructive Lung Disease (2015) Asthma, COPD, and asthma-COPD overlap syndrome. GINA and Global Initiative for Chronic Obstructive Lung Disease.

12. Sin DD, Miravitlles M, Mannino DM, Soriano JB, Price D, et al. (2016) What is asthma-COPD overlap syndrome? Towards a consensus definition from a round table discussion. Eur Respir J 48(3): 664-673.

13. Miravitlles M, Alvarez-Gutierrez F, Calle M, Casanova C, Cosío BG, et al. (2017) Algorithm for identification of ACO: Consensus between the Spanish COPD (GesEPOC) and asthma (GEMA) guidelines. Eur Respir J 49: 1700068.

14. Kitaguchi Y, Komatsu Y, Fujimoto K, Hanaoka M, Kubo K (2012) Sputum eosinophilia can predict responsiveness to inhaled corticosteroid treatment in patients with overlap syndrome of COPD and asthma. Int J Chron Obstruct Pulmon Dis 7: 283-289.

15. Wagener AH, De Nijs SB, Lutter R, Sousa AR, Weersink EJ, et al. (2015) External validation of blood eosinophils, $\mathrm{FE}(\mathrm{NO})$ and serum periostin as surrogates for sputum eosinophilsin asthma. Thorax 70(2): 115120.

16. Suissa S, Patenaude V, Lapi F, Ernst P (2013) Inhaled corticosteroids in COPD and the risk of serious pneumonia. Thorax 68(11): 1029-1036.

Your next submission with Juniper Publishers will reach you the below assets

- Quality Editorial service

- Swift Peer Review

- Reprints availability

- E-prints Service

- Manuscript Podcast for convenient understanding

- Global attainment for your research

- Manuscript accessibility in different formats

( Pdf, E-pub, Full Text, Audio)

- Unceasing customer service

Track the below URL for one-step submission https://juniperpublishers.com/online-submission.php 